\title{
Research on the Improvement of Competitiveness of Chain Business Enterprises with the System Theory
}

\author{
Xiaogang Yang \\ Chengdu Normal University, Chengdu, China \\ Email: 930761897@qq.com
}

Received 4 July 2016; accepted 16 July 2016; published 19 July 2016

Copyright (C 2016 by author and Scientific Research Publishing Inc.

This work is licensed under the Creative Commons Attribution International License (CC BY). http://creativecommons.org/licenses/by/4.0/

(c) (i) Open Access

\begin{abstract}
Chain business enterprises face increasing competition. With the system theory, the competitiveness structure of chain business enterprises is analyzed, and practical methods and measures for the improvement of their competitiveness are provided.
\end{abstract}

\section{Keywords}

\section{Chain Business Enterprises, Competitiveness, System Theory, Application}

\section{Introduction}

At present, after the golden developing period of 20 years, chain business enterprises are facing slow growth, weak consumption, rising costs, fierce competition and other difficulties and challenges [1]. The improvement of competitiveness of chain business enterprises is a matter of their survival and development. The researches of this aspect are relatively scattered. This paper uses the system theory to analyze the structure of competitiveness of chain business enterprises, and provides creative methods and measures for the improvement of their competitiveness.

\section{Overview of the System Theory}

The system theory was created by L.V. Bertalanffy, an American scientist. The system theory believes that integrity, relevance, grade structure, dynamic balancing, time sequence, etc. are the common basic characteristics of all systems. These characteristics are the basic ideas of the system theory and the basic principles of system approach. The system theory not only is the scientific theory reflecting the objective law, but also has the significance of scientific methodology. It can represent concepts, ideas, models and mathematical methods. 
The core of the system theory is the overall concept of the system. Bertalanffy emphasized that any system is an organic whole, but not mechanical combination or simple addition of each part. The system's overall function is the property which each element does not have in the isolated state. Aristotle said: "The whole is greater than the sum of the parts". Bertalanffy used his saying explain the integrity of the system, and opposed the idea of mechanism which describes the whole with parts. This idea believes that if the performance of elements is good, the overall performance must be good. The elements in the system do not exist in isolation. Each element in the system is in a certain position, and plays a certain role. The elements are correlated, and constitute an integral whole. Elements are elements in the whole. If they are separated from the system as a whole, the elements of will lose their effect.

The basic method of system theory is considering the object studied and treated as a system; analyzing the system structure and functions; studying the relation among and the law of change of the system, elements and the environment; and constantly optimizing the system. Everything in the world can be seen as a system. The system is universal. The universe, microscopic atoms, a swarm of bees, a machine, an enterprise and so on is a system. The whole world is a collection of the systems.

According to the system theory, the chain business enterprise is also a complex system. The chain business enterprise system is made up of chain headquarters subsystem, store subsystem and logistics and distribution subsystem. Chain headquarters subsystem is the command center of the enterprise, it stores implementation unified operation and management, unified development, allocation and management of enterprise's human, financial, logistics and product, the formation of the overall brand image; sub system of chain stores is terminal sales of the enterprises. It is directly dealing with customers, providing goods and services to customers, the final completion of the sales function of the enterprise; chain logistics and distribution subsystem is enterprise of power system, it directly for the stores to provide goods storage, distribution, delivery and logistics information. On the one hand, the operation of the chain business enterprise system is affected by micro environmental factors (suppliers, customers, competitors) and macro environment factors (policy, economy and society) outside the system. On the other hand, it is affected by the interaction and coordination among subsystems in the system.

\section{Overview of the Enterprise Competitiveness}

Enterprise competitiveness refers to the enterprise's comprehensive ability to realize its own value by cultivating its own resources and capabilities, obtaining, integrating and utilizing external resources and creating values for customers under the competitive market conditions. It also refers to a kind of unique skills and technology with which a company can bring special benefits to the customers. Competitiveness is the decisive ability for an enterprise to gain competitive advantage in the market competition.

The competitiveness of enterprises is divided into three levels. The first level is the product level, including product production and quality control ability of enterprises, enterprise services, cost control, marketing and $\mathrm{R}$ \& D ability; the second level is the system level, including the structure platform consisting of different operation and management elements internal and external environment of enterprises, resource interactions, operation mechanism of enterprise, enterprise scale, brand and property right system of enterprises; the third level is the core level, including enterprise culture centered on enterprise concept and enterprise values, the consistent internal and external enterprise image, enterprise innovation ability, differentiated and personalized enterprise features, sound finance, and excellent development goals. The first level is the competitiveness of on the surface; the second level is the competitiveness of the support platform; and the third level is the core competitiveness.

The enterprise competitiveness theory focuses on developing and studying the abilities of enterprises, giving full play to their own resources and ability advantages, and creating the competitive advantages better than for enterprises. At the same time, this theory requires enterprises to use their advantages of intangible resources and organizational abilities, and extend their assets stock and abilities, so as to gain lasting competitive advantages. As the market competition environment increasingly becomes complex, enterprises should not only strengthen various internal abilities, and improve the internal resource integration ability, but also pay attention to enterprises' connection with the external environment, use external resources, and set up the competitive cooperation concept. These requirements actually reflect views of the system theory. For smooth survival in the environment, a subject should pay attention to not only coordination of the internal elements, but also cooperation of external elements. 


\section{Analysis on the Structure of Competitive of Chain Business Enterprises}

The competitiveness of chain business enterprises refers to the comprehensive ability to continuously and effectively meet customer demands, and obtain the competitive advantages and their own development in a certain market environment compared with competitors. It is shown as the brand competitiveness externally, and service ability and logistics ability of the store market. Therefore, competitiveness factors of chain business enterprises include the resources allocation ability of headquarters, distribution ability of logistics system and market service ability of stores [2].

\subsection{The Resources Allocation Ability of Headquarters Refers to the Chain Headquarters' Ability of Enterprise Development, Configuration and Control}

The resources allocation ability of headquarters reflects the chain business enterprises' business areas, operation efficiency, management level, etc. It is the core competence of competitiveness of the chain business enterprises. Chain headquarters is the command center of the enterprise which implements unified operation management of stores; unified development, distribution and management of the enterprise's brand, manpower, finance, logistics and products; and forms the overall brand image. Corporate headquarters should focus on the coordination of external relations, build good channels, form strategic alliance with upstream and downstream enterprises, and give full play to the headquarters' heart and brain function [3]. In addition, the overall enterprise must pay special attention to the overall corporate strategy, combine with its own situation, take the cost leadership strategy, differentiation strategy and focus strategy, and implement the enterprise culture construction through the realization of vision.

\subsection{The Market Service Ability of Stores Is the Basic Ability of the Chain Business Enterprise}

Stores deal with customers every day, provide customers with goods and services, and ultimately complete the enterprise sales. So the operation of stores is directly reflected in the performance of headquarters. Consumers usually do not directly communicate with chain enterprises. Their cognition to the enterprise completely comes from their daily shopping experience, so if stores cannot meet the needs of the customers well and provide perfect services, this part of consumers will disappear. Therefore, the market service ability of stores should $b$ paid special attention to [4]. In addition, one of the key factors of success of chain enterprises is the location of the store. The headquarters should establish a set of perfect store location assessment system consistent with the characteristics of their enterprise. When the location is selected, the market potential analysis, investigation and analysis on business area, and other kinds of research should be completed, so as to provide scientific and rational data support to the confirmation of store address. After the confirmation of the location, the headquarters can provide stores with corresponding store plan, implementation standards and procedures, and provide the best service for the establishment of each new store.

\subsection{The Distribution Ability of Logistics System of a Key Part of the Competitiveness of Chain Business Enterprises}

The logistics distribution system is a specialized agency which directly provides stores with goods storage, distribution, delivery and logistics information processing. First, because they face the pressure brought by the increasingly complex business environment, chain enterprises must strengthen the concept of improvement of the ability of logistics, promote the informationalization and intelligentizing of distribution, and series and flexibility of services, and strengthen the execution of logistics distribution, so that the products can be quickly distributed from headquarters to the chain stores. Second, the headquarters should build the information platform, provide strong support to distribution, and provide guarantees to the product distribution of stores. Third, the chain enterprises should attach great importance to the strategic choice of the distribution mode, fully and effectively integrate logistics resources, break the distribution boundary among the stores, and improve the overall distribution capabilities.

\section{Methods and Measures for the Improvement of Competitiveness of Business Enterprises}

To survive in the fierce market competition, and become bigger and stronger, chain business enterprises must 
attach importance to the integration of internal and external resources, and constantly improve their own competitiveness. According to the analysis on the competitiveness structure of chain business enterprises, the author put forward the following methods and measures:

\subsection{Define the Product Positioning, and Build the Enterprise Image}

Product positioning means that through the market segmentation, the enterprise selects the market development space suitable for its operation for its products in the target market. Product positioning establishes the image and status of brand or product in the eyes of consumers, and the image and status should be different. It gives the product specific personality. It can adapt to the target market, and meet consumer demand, so as to improve the competitiveness of product or brand. In the face of fierce competition, chain business enterprises must have clear positioning, set up a clear business idea, and implement the differentiation strategy. They should pay special attention to customer orientation, and meet the needs of their customers through the analysis on consumer behaviors and demands. Enterprises should strive for differential operation, obvious distinguish the products and brand from those of competitive enterprises, and create their own store characteristics; and provide marketable products by understanding the needs of the consumers, according to the needs of the consumers. At the same time, they should pay close attention to the trend of the market change, adapt to the changing market, and ensure that they are not discarded by consumers. Therefore, enterprises should regularly make innovative marketing strategies, such as product promotion, relationship marketing and network marketing.

\subsection{Use the Advanced Technology, and Optimize the Logistics System}

In the operation of chain business enterprises, logistics technology plays a very important role. Excellent distribution ability of the logistics system can greatly reduce the total cost of the enterprise, and can improve the speed of response to customer demands. Chain enterprises should get rid of the bad habit of focusing on production and ignoring logistics in the industrial economic era, quickly build a modern logistics system, improve the ability of logistics, reduce logistics cost and create more values. Wal-Mart's success cannot go without its good technical facilities and advanced logistics management ability. It established the supplier information management system with and P \& G. At the same time, Wal-Mart spent a lot of money on communication satellite and other facilities, established a perfect distribution system in the global market, conducted comprehensive and indepth analysis on inventory cost, transportation cost and management cost of logistics cost, established the information integration system by strengthening the collaborative commerce of supply chain, reasonably planned, reduced inventory and improved the efficiency of management, so as to reduce logistics costs, greatly shorten the delivery time of the supply chain system, and win the competitive advantages for the enterprise.

\subsection{Innovate the High-Quality Service, and Create the Chain Brand}

Under the background of the era of global economic integration, the enterprise competition has gradually changed from product and price to the competition for customers. Whether customer service is perfect and continuously innovated has become an important indicator of the enterprise's survival [5]. Perfect service is the secret of enterprise success. A survey of American Marketing Strategy Plan Association shows that 91\% of customers will avoid companies with poor services, $80 \%$ of people look for companies with better services, and even $20 \%$ of people would rather spend more money for good service. In the fierce competition, product and technology advantages alone are not enough. Chain business enterprises must provide the professional, standard and continuously innovated services to impress customers. As consumers pay more attention to service experience, service brands have drawn more attention from chain business enterprises. Many service firms create their own service brands, such as banking, communication, retail and other industries. Even many manufacturing enterprises have began to build the service brands, such as household appliances, automobiles, electronics, tobacco and other production enterprises. Chain business enterprises should form and solidify their own highquality brands in the eyes of customers by continuously improving and innovating services and providing differentiated services, and continuously improve the market competitiveness of chain business enterprises [6].

\section{Conclusion}

Chain commercial enterprises are facing increasingly fierce competition. Application system on the idea and 
method of direct management of enterprise, make its headquarters subsystem, coordinated operation of the stores subsystem and logistics distribution sub system, through the implementation of a clear product positioning, to create corporate image; use of advanced technology, optimize logistics system; innovation and high quality services, to create a chain brand measures, and constantly improve the competitiveness of chain commercial enterprises.

\section{References}

[1] Li, K.X. and Lu, Y. (2015) Research on the Improvement Strategy of Brand Competitiveness of Catering Chain Enterprise in China. Economic Research Guide, No. 9.

[2] Wang, C.C. (2012) Discussion about AHP Evaluation of the Competitiveness of Chain Retail Enterprises. Journal of Wuhan Polytechnic University, No. 2.

[3] Dong, S.H. (2010) Discussion about Competitiveness of Chain Enterprises Based on the Resources and Abilities. Commercial Times, No. 21.

[4] Hu, D.L., Lu, F.C. and Wang, H.L. (2007) Enterprise Competitiveness Decision and Forming Process. Management World, No. 10.

[5] Ji, M. (2013) Research on Evaluation and Improvement of Competitiveness of Home Appliance Retail Chain Enterprises in China: Take Gome Group as an Example. Journal of Political Economy and Management, No. 6.

[6] Qiu, X.P. (2015) Strategic Thinking on Promoting the Competitive Power of the Brand Chain Retail Enterprises. Modern Business, No. 25.

\section{Submit or recommend next manuscript to SCIRP and we will provide best service for you:}

Accepting pre-submission inquiries through Email, Facebook, Linkedin, Twitter, etc A wide selection of journals (inclusive of 9 subjects, more than 200 journals)

Providing a 24-hour high-quality service

User-friendly online submission system

Fair and swift peer-review system

Efficient typesetting and proofreading procedure

Display of the result of downloads and visits, as well as the number of cited articles

Maximum dissemination of your research work

Submit your manuscript at: http://papersubmission.scirp.org/ 